Andrzej Koszewnik*, ZdzisŁaw GosiewsKi*

\title{
MODELLING OF THE SEAT SUSPENSION SYSTEM FOR THE VIBRATION CONTROL SYSTEM
}

\begin{abstract}
In this paper, a model of the passive seat suspension system is designed. To verify the model the excitation signals are modelled by using generator embedded to Simulink software. Additionally, the excitation signal is filtered with the use of the Butterworth filters. The vibro-isolation properties of the system are calculated on the basis of the ratio transmissibility of the vibration. The investigations proved that the designed system is correctly modelled and the system damps the vibration speciously in the most dangerous frequency range up to $20 \mathrm{~Hz}$.
\end{abstract}

Keywords: seat suspension, Butterworth filter, modelling, transmissibility

\section{MODELOWANIE PASYWNEGO UKŁADU ZAWIESZENIA SIEDZISKA}

$W$ artykule przedstawiono model pasywnego układu zawieszenia siedziska operatora autobusu na przykładzie siedziska firmy ISRI. Na potrzeby badań losowe sygnały wymuszenia zostały zamodelowane w środowisku Matlab/Simulink. Dodatkowo, na potrzeby badań, sygnały wymuszenia zostały przefiltrowane z wykorzystaniem filtru Butterworth. Właściwości wibroizolacyjne układu zostały wyznaczone na podstawie kryterium wspótczynnika przenoszenia drgań. Badania symulacyjne wykazały tlumienie drgań przez układ szczególnie w najbardziej niebezpiecznym zakresie częstotliwości do 20 Hz.

Stowa kluczowe: pasywny układ zawieszenia, filtr Butterworth, wspótczynnik przenoszenia drgań, Matlab/Simulink

\section{INTRODUCTION}

Suspension seats with a cross mechanism are widely used in the off-road machinery or buses to reduce the vibration transmitted from the vehicle floor to the vehicle operator. A conventional solid foam or sprung foam can't damp the vibrations at such low frequencies $(1-15 \mathrm{~Hz})$ in a satisfying way, especially in such huge vehicles. Moreover, longer stay of vehicle operator in such vibration environments may cause irreversible changes in the human health (Gunston 2000, Afework and Sankar 1994, Wei and Griffin 1998). Especially, it is dangerous for human organs, the resonant frequencies of which are included in the mentioned range of frequencies (Segla and Trisovic 2013). For such frequencies, even small amplitude disturbances may act to amplify the resonance vibrations of particular human organs. Ipso facto these vibrations may lead to pathological phenomena of the organs and their injury.

Investigations carried out in the Bialystok Public Transport Company (BPTC) lead to the testing of such suspension. The first experimental tests made in BPTC using the Bruel\&Kjear accelerometer have shown a strong transmission of vibrations from the vehicle floor to the vehicle seat during bus stop, especially for 12 or 15 meters long bus. The obtained frequencies of vibrations have been in the range of $1-15 \mathrm{~Hz}$, so to improve the conditions of the work of the operator of buses these vibrations need to be reduced.

This paper is divided into two parts. In the first part the mathematical model of passive seat suspension has been modelled in accordance to balance forces acting on the seat.
In the second part the model has been tested for different excitation signals. The obtained results in further investigations allowed us to rebuild the model by using smart materials.

\section{THE MODEL OF THE SEAT SUSPENSION SYSTEM}

The passive system of the seat suspension with a cross mechanism, a hydraulic damper and a pneumatic spring is shown in figure 1 . This mechanism reduces the vibration transmitted from the vehicle floor to the vehicle operator, especially in vertical direction. Then, the whole process of the design of the mathematical model of the system is connected with this direction of the vibration.

In accordance to figure 1 the equation of motion of the passive system is expressed by:

$$
m_{0} \ddot{q}_{0 z}=F_{a s}+F_{d}+F_{f f}+F_{b u}+F_{b d}+F_{g}
$$

where: $F_{a s}$ - force derived from the pneumatic spring, $F_{d}$ force derived from the hydraulic damper, $F_{f f}$ - friction force of the system, $F_{b u}$ - force derived from the bump up, $F_{b d}-$ force derived from the bump down, $F_{g}$ - gravity force.

In accordance to the scheme shown in figure 1, the direction of action of both forces $F_{a s}$ and $F_{d}$ depends on a pitch angle of an arm cross mechanism relative to their fixed point (2). Then, the change in this angle is caused by the change in the length of both elements: spring elements $l_{a s}$ and the hydraulic damper $l_{d}$ and finally in the change of parameters

* Bialystok University of Technology, Faculty of Mechanical Engineering, Department of Automatics Control and Robotics,

Wiejska 45C Street, 15-351 Bialystok, Poland, a.koszewnik@pb.edu.pl, z.gosiewski@pb.edu.pl 
$\delta_{a}$ and $\delta_{d}$ which are presented in table 1 , respectively. So, in accordance to figure 2 and table 1 the obtained analytical equations for forces of spring elements and the hydraulic damper are given in the last row of table 1 .

\section{Table 1}

Equations for the air spring and the hydraulic damper

\begin{tabular}{|l|c|}
\hline Air spring & Hydraulic damper \\
\hline$l_{a s}=\sqrt{\begin{array}{l}(-r \cos \alpha(t)+c \sin \alpha(t)+b)^{2} \\
+(-r \cos \alpha(t)+c \sin \alpha(t)+a)^{2}\end{array}}$ & $l_{d}=\sqrt{\begin{array}{l}\left(r_{2} \cos \alpha(t)+d \sin \alpha(t)-r_{1} \cos \alpha(t)+e \sin \alpha(t)\right)^{2} \\
+\left(r_{2} \sin \alpha(t)+d \cos \alpha(t)-\left(R-r_{1}\right) \sin \alpha(t)+e \cos \alpha(t)\right)^{2}\end{array}}$ \\
\hline$\delta_{a s}=\frac{q_{0 z}-q_{S z}-q_{d z}}{l_{a s}-l_{d a s}}$ & $\delta_{d}=\frac{q_{0 z}-q_{S z}-q_{d z}}{l_{d}-l_{d d}}$ \\
\hline$F_{a s}=\frac{1}{\delta_{a s}} A_{e f}\left(p_{a s}-p_{0}\right)$ & $F_{d}=\frac{1}{\delta_{d}}\left\{\begin{array}{l}\zeta_{(B \rightarrow A)} \frac{\rho_{d}}{2}\left(\frac{A_{B}\left(\dot{q}_{0 Z}-\dot{q}_{S Z}\right)}{\delta_{d} A_{o}}\right)^{2} A_{B} \Rightarrow \dot{q}_{0 Z}-\dot{q}_{S Z} \geq 0 \\
-\zeta_{(B \rightarrow A)} \frac{\rho_{d}}{2}\left(\frac{A_{A}\left(\dot{q}_{0 Z}-\dot{q}_{S Z}\right)}{\delta_{d} A_{o}}\right)^{2} A_{A} \Rightarrow \dot{q}_{0 z}-\dot{q}_{S Z}<0\end{array}\right.$ \\
\hline
\end{tabular}

where: $\zeta_{(B \rightarrow A)}-$ loss factor of fluid by flew with chamber $B$ to $A, \zeta_{(A \rightarrow B)}-$ loss factor of fluid by flew with chamber $A$ to $B$, and:

$$
\alpha(t)=\arcsin \left(\frac{q_{01}-q_{S z}}{R}\right)
$$

Other forces included in equation (1) $\left(F_{f f}, F_{b d}, F_{b u}, F_{g}\right)$ are also expressed in an analytical way. Therefore, in accordance to equations (3) - (6) and the last row of table 1, the scheme block of the passive system of the seat suspension has been created.

$$
\begin{aligned}
& \dot{F}_{f f}=-k_{f f}\left(\dot{q}_{0 z}-\dot{q}_{S z}\right)+\gamma_{f f}\left|\dot{q}_{0 z}-\dot{q}_{S z}\right| F_{f f}+\beta_{f f}\left(\dot{q}_{0 z}-\dot{q}_{S z}\right)\left|F_{f f}\right| \\
& F_{b d}=\left\{\begin{array}{rr}
k_{d 3}\left(q_{0 z}-q_{s z}-q_{d z}\right)^{3}+k_{d 1}\left(q_{0 z}-q_{s z}-q_{d z}\right) & \text { for } q_{0 z}-q_{S Z}<q_{d Z} \\
0 & \text { for } q_{0 z}-q_{S Z} \geq q_{d Z}
\end{array}\right. \\
& F_{b u}=\left\{\begin{array}{rr}
k_{u 3}\left(q_{0 z}-q_{s z}-q_{u z}\right)^{3}+k_{u 1}\left(q_{0 z}-q_{s z}-q_{u z}\right) & \text { dla } q_{0 Z}-q_{S Z}>q_{U Z} \\
0 & \text { dla } q_{0 z}-q_{S Z} \leq q_{U Z}
\end{array}\right. \\
& F_{g}=-m_{0} g
\end{aligned}
$$

where: $q_{0 z}-$ displacement of the down platform, $q_{s z}$ - displacement of the upper platform, $k_{f f}$ - stiffness of the friction force, $\beta_{f f}$ and $\gamma_{f f}$-parameters influencing the shape of hysteresis.

All above forces have been used to design the mathematical model of the passive system in the Matlab/Simulink

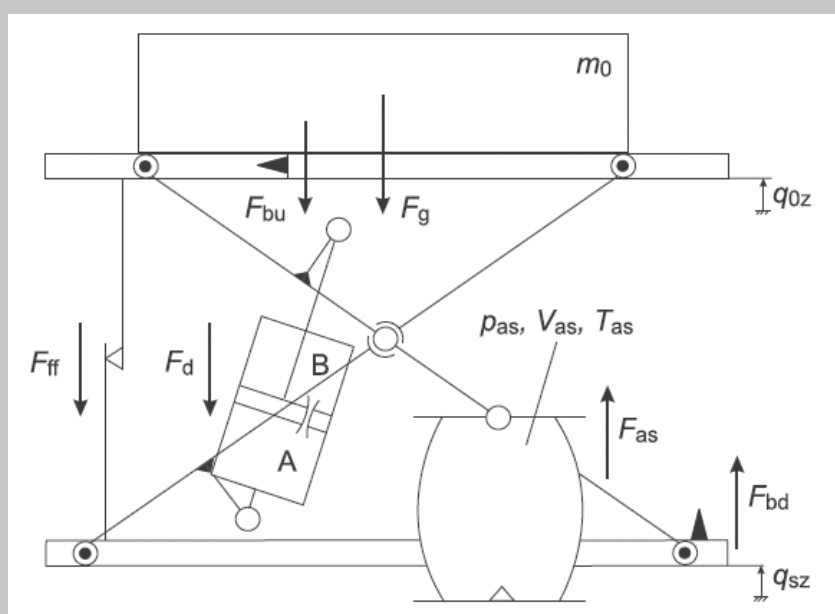

Fig. 1. The passive system of seat suspension (Maciejewski 2012) a)

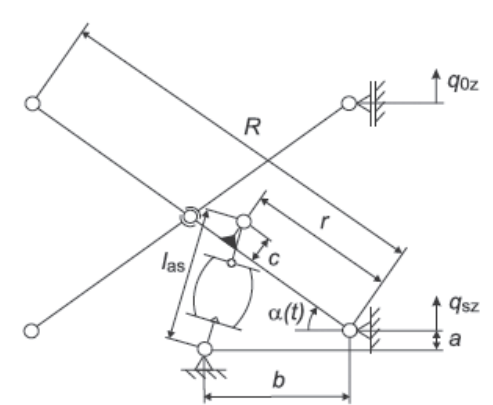

b)

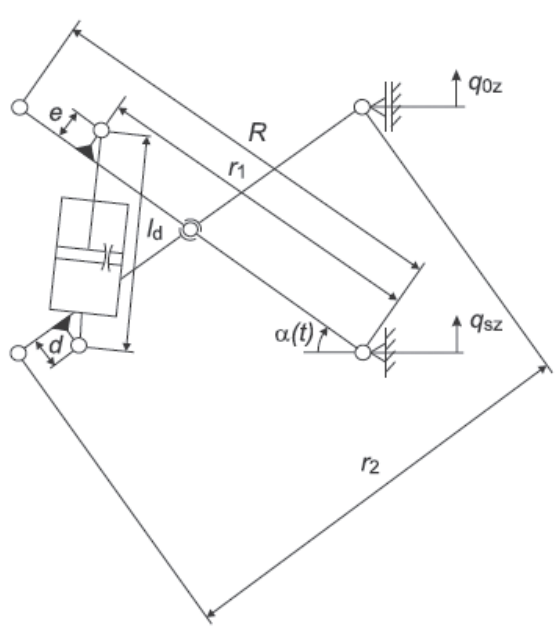

Fig. 2. Kinematic model of the system with: a) the force of the air spring, b) the force of the hydraulic damper 
software. The whole system is shown in figure 3 . In accordance to figure 3, all sub-forces in the system consist of one input $R S$ which is described relative to the location of the cross mechanism. Therefore, this value equals the difference between the shift displacement of the upper platform $q_{0 z}$ and the shift displacement of the down platform $q_{s z}$ of the cross mechanism (see fig. 1). Additionally, the static deflection of the system equal to 0,135 according to the data sheet of the considered type of the seat - ISRI company - is included.

\section{THE EXCITATION SIGNAL OF THE MODEL}

Vibrations in the frequency range of $1-10 \mathrm{~Hz}$ are the most typical vibrations which act on a vehicle operator of buses or other working machines (Wu and Griffin 1996). For further investigations as an excitation signal the random signal has been used. The signal is modelled with the random number generator (rand) embedded to the Matlab/Simulink software:

$$
\ddot{q}(t)=a_{\max } \operatorname{rand}\left(\frac{t}{t s}\right)
$$

where: $\ddot{q}(t)$ - acceleration of the vibration signal in vertical direction, $a_{\max }-$ maximum amplitude of the vibration signal, $t$ - time, $t_{s}$ - sampling time $\left(t_{s}=0.001 \mathrm{~s}\right)$.

Amplitudes of excitation signals are random, so it was not possible to find out the exact value of the signal in time domain. The probability density function of the signal $\ddot{q}(t)$ for the parameters: $\mu=0,004$ and $\sigma=5.7666$ of Gaussian disturbance is presented in figure $4 \mathrm{~b}$ (Heinzel 2002). So, to simplify further investigations, the probability density function

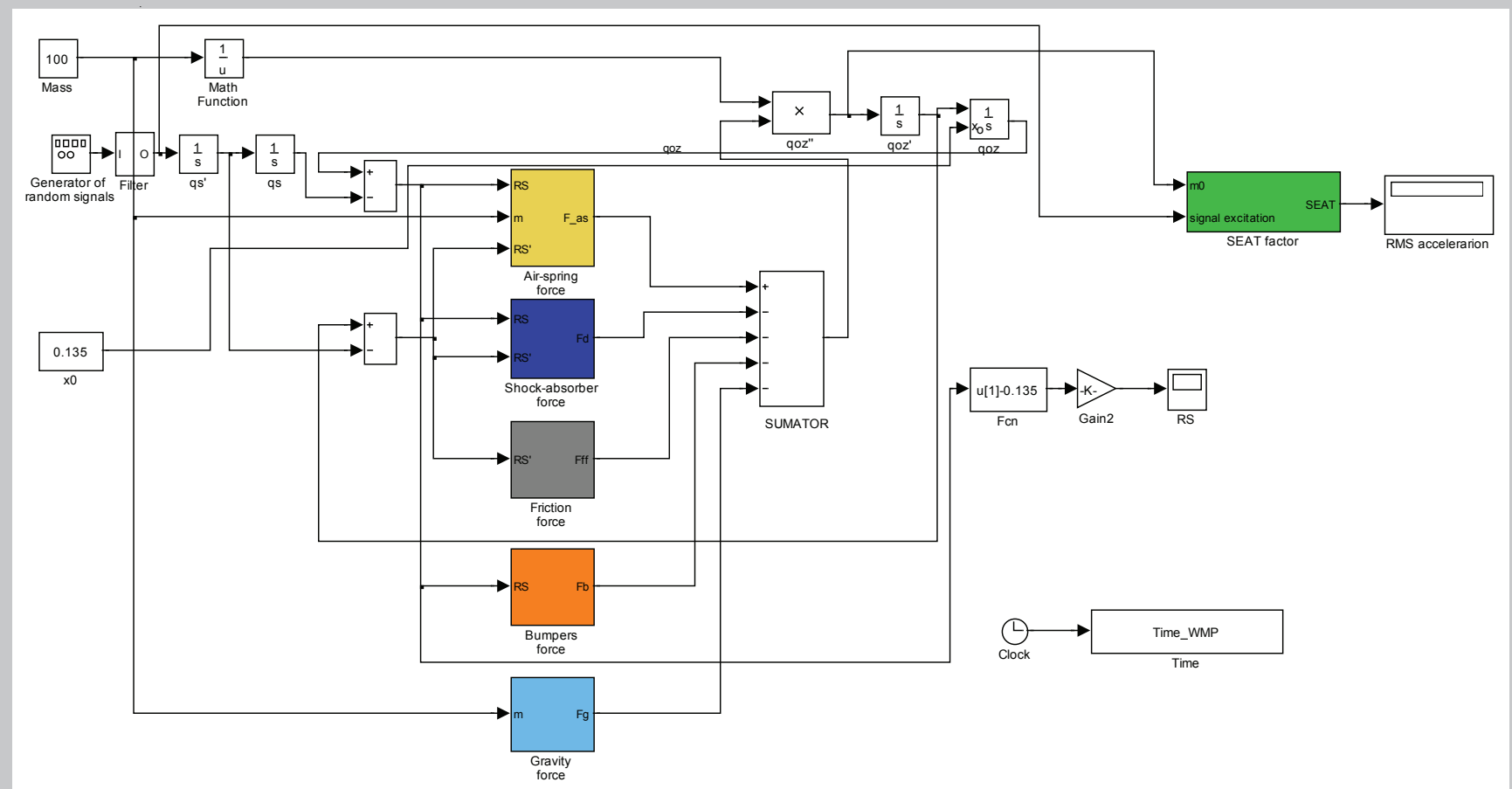

Fig. 3. Block scheme of the passive system of seat suspension
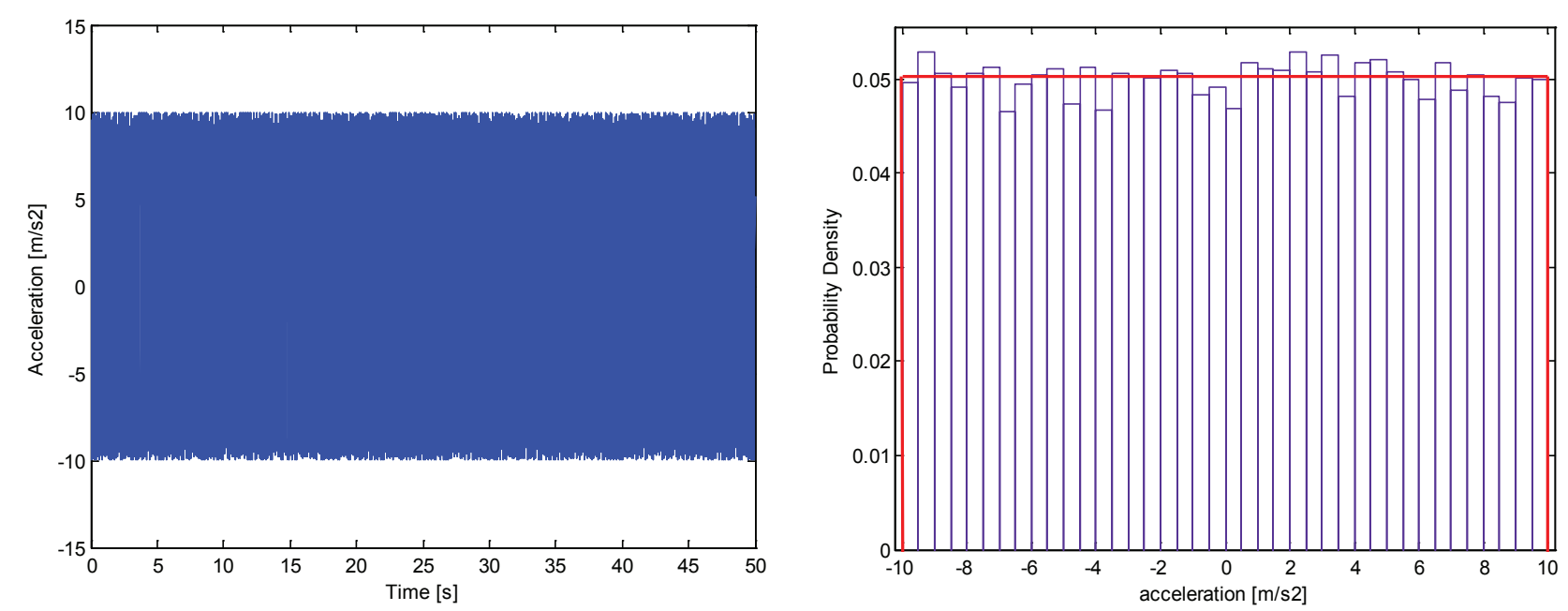

Fig. 4. Random signal in time domain(a), probability density function signal $\ddot{q}(t)(b)$ 
is expressed as a constant value equal 0,05 what is shown in figure $4 \mathrm{~b}$ (red line).

$$
p(\ddot{q}(t))=\left\{\begin{array}{ccc}
0 & \text { for } & \ddot{q}(t)<-10 \\
0.05 & \text { for } & -10 \leq \ddot{q}(t) \leq 10 \\
0 & \text { for } & \ddot{q}(t)>10
\end{array}\right.
$$

The obtained excitation signal as a random acceleration signal is filtered with low-pass and high-pass filters of Butterworth. The main reason for the use of these filters is to shape the amplitude of the signal excitation. In the considered case a low pass filter with the cut-off frequency of $f_{\mathrm{c}}=10 \mathrm{~Hz}$ and a high pass filter with the cut-off frequency of $f_{\mathrm{c}}=0,5 \mathrm{~Hz}$ are used. Their transfer functions are as follows:

$$
\begin{aligned}
& H_{H P}(s)=\frac{0.01027 s^{4}}{0,01027 s^{4}+81.02 s^{3}+32,71 s^{2}+82.09 s+1} \\
& H_{L P}(s)=\frac{1}{6.416 e+8 s^{4}+6.482 e 5 s^{3}+1.308 e 4 s^{2}+1}
\end{aligned}
$$

\section{ESTIMATION OF THE VIBRO-ISOLATION SYSTEM}

One of the performance indexes of the vibro-isolation system is the ratio of transmissibility of vibration (TFE). Since this value can be calculated simply, this performance index is very often used to estimate the ability of the passive system to reduce the vibrations. So, according to equation (11) this value has been calculated only for the vertical direction of the vibrations:

$$
T F E_{z}=\frac{\left(q_{0 z w}\right)_{R M S}}{\left(q_{s z w}\right)_{R M S}}
$$

where: $\left(q_{0 z w}\right)_{R M S}$ - root mean square value of acceleration of vibration of $m_{0},\left(q_{s z w}\right)_{R M S}$ - root mean square value of acceleration of vibration of the excitation signal.

Above RMS values of vibrations are expressed by the following equation:

$$
\left(q_{S z w}\right)_{R M S}=\sqrt{\frac{1}{t} \int_{0}^{t} \ddot{q}_{S Z W}(t)^{2} d t}
$$

$$
\text { and }\left(q_{o z w}\right)_{R M S}=\sqrt{\frac{1}{t} \int_{0}^{t} \ddot{q}_{O Z W}(t)^{2} d t}
$$

where: $q_{s z w}$ - the frequency weighted acceleration of the excitation signal, $q_{0 z w}$ - the frequency weighted acceleration of the measured signal, $t$ - time of simulation $(0-50 \mathrm{~s})$.

The proper value of the ratio of TFE strongly depends on the weighting curve. Taking into account the health, comfort and perception of the machine operator only curve $\mathbf{W}_{\mathrm{k}}$ is included in further consideration. The mentioned curve is created by the cascade joint of four filters: low-pass $H_{l i}(s)$, high-pass $H_{h i}(s)$, crossing acceleration-velocity $H_{a v}(s)$, and $H_{b}(s)$ in the frequency range of $0,4-100[\mathrm{~Hz}]$ according to (ISO 2631-1 1997). Then, on the basis of the respective

Table 2

Parameters of the transfer functions of the frequency weightings (ISO 2631-1 1997)

\begin{tabular}{|c|c|c|c|c|c|c|c|c|c|}
\hline \multirow{2}{*}{ Curves } & \multicolumn{2}{|c|}{ Band-limiting } & \multicolumn{2}{|c|}{ Acceleration - velocity transmission } & \multicolumn{4}{c|}{ Upward step } \\
\cline { 2 - 11 } & $f_{1}[\mathrm{~Hz}]$ & $f_{2}[\mathrm{~Hz}]$ & $f_{3}[\mathrm{~Hz}]$ & $f_{4}[\mathrm{~Hz}]$ & $Q_{4}$ & $f_{5}[\mathrm{~Hz}]$ & $Q_{5}$ & $f_{6}[\mathrm{~Hz}]$ & $Q_{6}$ \\
\hline $\mathbf{W}_{\mathbf{k}}$ & 0.04 & 100 & 12.5 & 12.5 & 0.63 & 2.37 & 0.91 & 3.35 & 0.91 \\
\hline
\end{tabular}
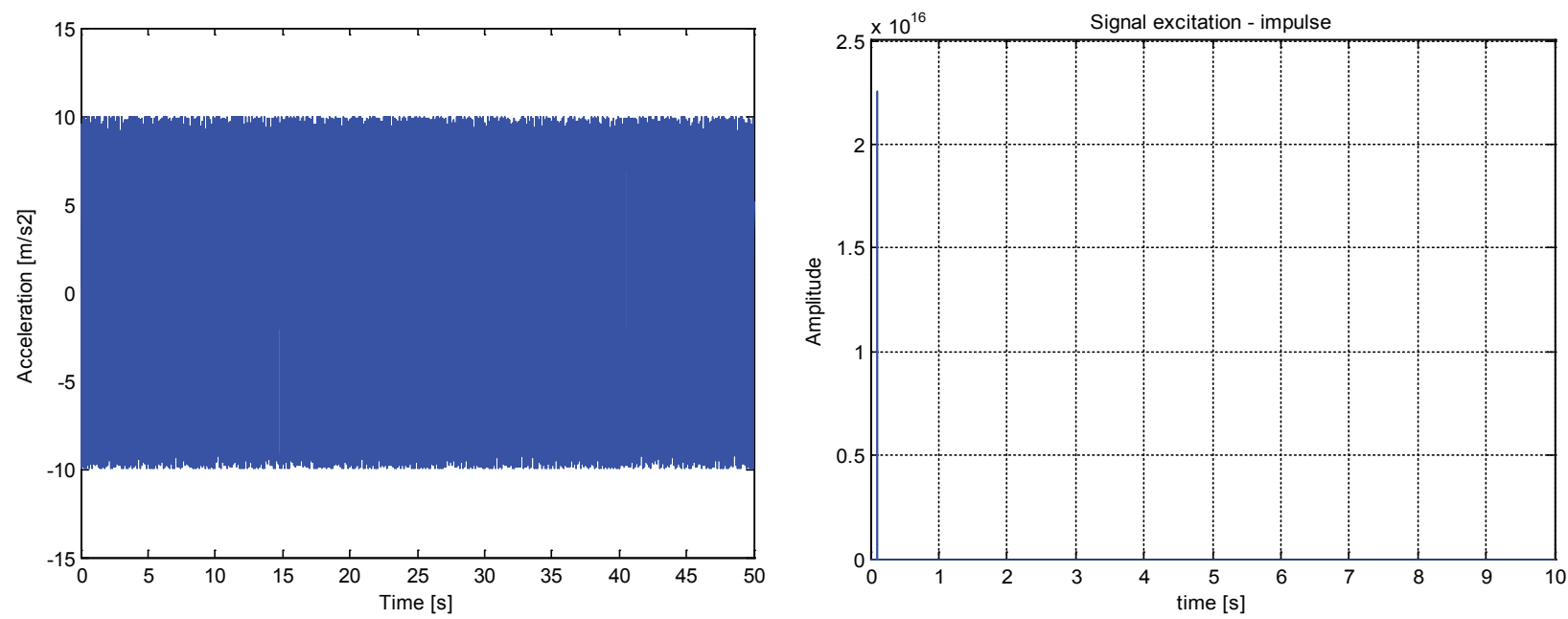

Fig. 5. Calculated values of TFE for different types of excitation: a) random signal b) impulse signal 
transfer functions of the filters and their particular cut-off frequencies (tab. 2) the transfer function $H_{k}(s)$ is obtained:

$$
\begin{aligned}
& H_{l i}(s)=\frac{s^{2}}{s^{2}+3.554 s+6.315} \\
& H_{h i}(s)=\frac{394760}{s^{2}+888.5 s+394760} \\
& H_{a v}(s)=\frac{78.54 s+6168}{s^{2}+124.7 s+6168} \\
& H_{b}(s)=\frac{s^{2}+15.86 s+216.7}{s^{2}+22.78 s+429.7} \\
& H_{k}(s)=H_{l i}(s) \cdot H_{h i}(s) \cdot H_{A c}(s) \cdot H_{b}(s)
\end{aligned}
$$

\section{SIMULATION TESTS}

According to figure 3 all calculations have been carried out for the isolation mass equal to $100 \mathrm{~kg}$, time simulation of $50 \mathrm{~s}$ and different types of excitation signals: random and impulse, respectively. The typical excitation signals like: step or sinusoidal signals have not been included because the most typical of excitation signals that are met in real machines are random signals. In figure 5 one can see that the effect of damping the vibrations has been achieved. The obtained values of transmissibility are less than unit (TFE $=0,523$ - random signal, TFE $=0,7602-$ impulse signal), so the passive system has reduced the vibrations in the considered frequency band.

\section{CONCLUSION AND FUTURE WORK}

This paper presents a process of modelling the passive system of the seat suspension of the Solaris bus by using the Matlab/Simulink software (Kandhasamy 2010). Furthermore the model shown in figure 3 has an additional block SEAT Factor used to calculate the ratio of transmissibility of the vibration as one of the performance indices of the vibro-isolation system. The obtained values of TFE have proved the correct operation of the system for the chosen signal excitations. Those results are correct and encouraging to future work.

Currently, the system is being rebuilt and the hydraulic damper is replaced by piezo-actuators. The first results in time and frequency domain have already been obtained for these piezo-actuators. The results of the active vibration damping system for the seat suspension will be presented soon in the next paper.

\section{References}

Afework Y., Sankar S. 1994, An analytical and experimental investigation of the driver seat-suspension system. Vehicle System Dynamics, vol. 23, pp. 501-524.

Gunston T. 2000, An investigation of suspension seat damping using a theoretical Model. A paper presented to the 35th meeting of the U.K. Group on Human Response to Vibration.

Heinzel G. 2002, Spectrum and spectral density estimation by the Discrete Fourier transform (DFT).

[http://www.rssd.esa.int/SP/LISAPATHFINDER/docs/Data_Analysis/ GH_FFT. pdf].

ISO 2631-1 1997, The International Standrad, Mechanical vibration and shock-evaluation of human exposure to whole-body vibration. Part.1 General requirements.

Kandhasamy S. 2010, DFT, PSD and Matlab. pp. 1-6.

Maciejewski I. 2012, Kształtowanie właściwości wibroizoalacyjnych uktadów redukcji drgań stosowanych w maszynach roboczych. Koszalin.

Segla S, Trisovic N. 2013, Modelling and Optimization of Passive Seat Sus pension. American Journal of Mechanical Engineering, vol. 1, No. 7, pp. 407-411.

Wei L., Griffin M.J. 1998, The prediction of seat transmissibility from measures of seat impedance. Journal of Sound and Vibration, vol. 214 (1), pp. 121-137.

Wu X., Griffin M.J. 1996, Towards the standardization of a testing method for the end-stop impacts of suspension seats. Journal of Sound and Vibration, vol. 192(1), pp. 307-319. 